\section{Earth, Moon and Planets}

By Fred L. Whipple. (Harvard Books on Astronomy.) Pp. vii +293. (London: J. and A. Churchill, Ltd., 1946.) $18 s$.

1 WIS is one of a series of books from Harvard Observatory, all of which are compiled by specialists in their own particular sphere. The present volume gives up-to-date information about the bodies in the solar system, and as it is written in language which is almost entirely free from technicalities, it will appeal to a wide circle of readers. The author devotes some space to a consideration of origins and evolution, especially to the origin of lunar craters and to the origin of the planetary system. $\mathrm{He}$ favours the volcanic theory of the formation of craters on the moon, but admits that meteors may be responsible for the more recent craters-those with ray systems and some of the whiter ones, and also for many of the craterlets and crater pits. In dealing with the origin and evolution of the planets in Chapter 14, he examines the arguments for and against the planetesimal hypothesis of Chamberlin and Moulton and the tidal theory, and gives his opinion in favour of a fairly rapid condensation as more probable than an accretion; but he admits that the choice between the two processes is not conclusive as the problems are complex.

A most valuable feature of the book is the planet finder and the star chart by means of which the positions of the planets can be located up to 1970 . This portion will prove most helpful to many readers who want to know the positions of the planets from month to month.

The book is well illustrated by 140 figures, more than half of which are photographs.

Some minor corrections should be made in the next edition. It is usual now to accept the Astronomer Royal's recent determination of the solar parallax and to adopt $93,005,000$ miles, not $92,870,000$ miles (p. 3), as the astronomical unit. Although the 1931 approach of Eros is mentioned on p. 48, Hinks's value for the solar parallax is given. The extra motion of the perihelion of Mercury's orbit is more nearly $43^{\prime \prime}$ per century than "about $50^{\prime \prime}$ (p. 28). The velocity of escape from the solar system (presumably at the distance of an astronomical unit from the sun) is not 45 but 26 miles per second (p. 78). Further, meteors do not move with velocities of 45 miles per second relative to the sun (p. 78); this is their maximum velocity relative to the earth.

\section{Davidson}

\section{Statistical Analysis in Biology}

By Dr. K. Mather. Second edition, revised and enlarged. Pp. iv + 268. (London: Methuen and Co. Ltd., 1946.) 16s. net.

$\mathrm{T}$

HE profound effect which R. A. Fisher has had on the interpretation of biological data has been mediated through a book which most biologists can only dimly understand at first. The meanings of the new ideas put forward in this book are often not fully explained; but the interested reader is stimulated to think them out for himself. More detailed expositions of many of the new statistical methods are contained in various other books ; but Dr. Mather's book is, so to speak, the authorized version. The author is primarily a biologist; but he has evidently devoted much thought to the meaning of the quantities that can be calculated from a set of data and their relation to one another. His book is illustrated with examples, and the reasoning is given at length so that much of it can be read fairly rapidly.

This book has been out of print for some time and the new edition will be welcomed. It is much the same as the first edition except that it contains a valuable new chapter dealing with two transformations which may be applied to percentages $-p=\sin ^{2} \varphi$ and probits. In each case, the method is explained and one example is worked out.

\section{The Bathe}

An Ecstasy. By Marie Carmichael Stopes. Pp. iv + 19. (London: Alexander Moring, Ltd., 1946.) $5 s$.

F the lyrical quality of this poem, as indeed of all Dr. Stopes' verse, there is no question. From the first apparently effortless stanza :

"Brown rocks have sucked in all the sun's warm rays To over brimming, till they fill the air

To fine enraptured whirlpuffs gliding where

They quiver up the bank of sheltered bays",

continuing through the whole poem with the same musical consistency. Phrases slip into place with the same facility as their author appears to glide into the sea. Students of form would benefit by observing such unobtrusive craftsmanship.

"An Ecstasy" is no idle description; here is a spirit bubbling with almost youthful ebullience, whose flight is as spacious as it is melodic.

Individual lines are admirable:

"And lave my feet among these lambent pearls." "The swirl subsiding silence broods in me." "Deep clarity of blue translucence calls more than my body to be permeate."

But the author's enraptured journey tends to veil her powers of discretion. Imagination is not necessarily art.

"Soon my salt tanged palms

Vie with intoxicating scent brewed balms,

To yield sweet odours to the sun drenched sky.

Short golden hairs, minutest flagstaffs rear

Each on its tiny mound, but soon they cling

Content to nestle close like folded wing."

Avoiding this misguided sensuousness, Dr. Stopes would be a poet of quality, and a stronghold for readers who deplore the absence of buoyancy in modern poetry.

Margaret Howard

Reports of the Progress of Applied Chemistry Issued by the Society of Chemical Industry. Vol. 29, 1944. Pp. 574. (London: Society of Chemical Industry, 1946.)

HE present volume of this very useful review of the progress of industrial chemistry contains the usual sections. A notable feature is the inclusion of statistics in many cases where these had been held up during the war period. Those on coal make dismal reading. The abstracts are usually quite brief, so that it is scarcely possible to select any topics for special mention. Attention may perhaps be directed to some interesting information on moth-proofing (p. 91), on molecular weights of cellulosic materials (p. 101), plastics (p. 255), soils and fertilizers (p. 364), foods (p. 418), and fine chemicals and medicinal substances (p. 450). Many of these topies, it will be seen, are of general interest in various fields. The volume contains a very large amount of information and is well produced and indexed. 